\title{
T lymphocytes maintain structure and function of fibroblastic reticular cells via lymphotoxin (LT)-B
}

\author{
Lintao Zhao ${ }^{\dagger}$, Lina Liu ${ }^{\dagger}$, Jianbao Gao, Yang Yang, Chunyan Hu, Bo Guo ${ }^{*}$ and Bo Zhu*
}

\begin{abstract}
Background: Although a lot is known about how Fibroblastic Reticular Cells (FRCs) can regulate T lymphocytes (T cells), little is understood about whether or how T cells can regulate FRCs.

Results: This study shows that the absence of T cells inhibited the secretion of ER-TR7 by splenic FRCs, induced the structural disorder of FRCs, down-regulated the expression of the chemokine ligands CCL21 and CCL19, and weakened the homing ability of T cells to the spleen of nude mice. Transfusion of T cells from BALB/c mice restored the structure and functions of FRCs and recovered them. The expression of lymphotoxin (LT)-B was significantly downregulated in the absence of $T$ cells from nude mice and was recovered after the transfusion of $T$ cells. After the occlusion of the LT-B receptor, the FRCs' structure and functions were not restored by transfusion of T cells.

Conclusions: These data reveal that the absence of T cells will subject spleen FRCs to structural and functional abnormality, and weaken the homing ability of $\mathrm{T}$ cells to the spleen. These changes are attributed to the T-cell- derived LT-B.
\end{abstract}

Keywords: FRCs, Spleen, CCL21, CCL19, Lt-B

\section{Background}

The generation of immune responses requires the interaction of rare antigen-specific $\mathrm{T}$ lymphocytes ( $\mathrm{T}$ cells) with dendritic cell (DC) presenting the appropriate antigen. The spontaneous interaction between them is rare in the body and only occurs in specific structures, namely the secondary lymphoid organs (SLOs) [1]. The interactions are highly dependent on their architecture [2]. SLOs contain several compartments characterized by specific resident stromal cells. The most important compartments are the B-cell and T-cell zones. The B-cell zone is composed of follicular dendritic cells (FDCs), which produce CXCL13 to attract B cells [3]. The T-cell zone (paracortex) is rich in fibroblastic reticular cells (FRCs) that express the chemokine ligands CCL19 and CCL21 to attract naive T cells and DCs [4].

FDCs are well-established players in the B-cell responses, but the importance of T-zone FRCs in adaptive immunity has been noticed only recently. FRCs can secrete abundant

\footnotetext{
*Correspondence: 25483098@qq.com;b.davis.zhu@gmail.com

${ }^{\dagger}$ Equal contributors

Institution of Cancer, Xinqiao Hospital, Third Military Mediecal University, Chongqing 400037, China
}

extracellular matrix (ECM) and form specialized conduits that transport small molecules to the T zone [5]. FRCs enwrap these conduits to form a 3-dimensional cellular scaffold that allows DCs to adhere and recirculate $\mathrm{T}$ cells to migrate along, thereby improving the probability of successful encounters between activated DCs and naive T cells [6].

Previous studies suggest that reduced expression of the homeostatic chemokines in lymphoid tissues will inhibit the aggregation of $\mathrm{T}$ cells and DCs in the T-cell zone in SLOs and thereby lower the probability of encounter between antigen-specific T cells and DCs, thus weakening the immune response intensity [7]. Besides CCL19/21, FRCs also produce interleukin (IL)-7 to promote the survival of naive T-cells [8]. Past studies focus on the effects of FRCs on T cells, but not on the effects of T cells on FRCs, which is mainly studied in the field of HIV infection. Earlier studies on HIV infection indicate that $\mathrm{T}$ cell absence could decrease the IL- 7 secretion by FRCs, thereby further precluding the survival of $\mathrm{T}$ cells [9]. However, there is no report about whether $\mathrm{T}$ cells can affect the secretion of CCL19 and CCL21 by FRCs. Previous investigations showed that virus could spread in an uncontrolled fashion in $\mathrm{LTb}^{-1-}$ mice [10]; that 
expression of IL-7 in FRCs from LT-B knockout mice was significantly down-regulated [11]; and that LT-B is mainly expressed in T cells [12], which together suggest that the FRC-regulated T cells may also affect FRCs through secretion of factors such as lymphotoxin (LT)-B.

In this study, with a spleen model, we comprehensively analyzed the morphology, organization and function of FRCs in the absence of T cells. Our results indicate that in the absence of $\mathrm{T}$ cells significant changes could occur, both, in the structure of FRCs and in the secretion of CCL21/19 by FRCs, which is likely mediated through the expression of LT-B. These results suggest that T cells can play an important role in maintaining FRC function and is probably achieved through LT-B.

\section{Results}

The conduits of FRCs were destroyed in the absence of T cells We first histologically studied the effects of $\mathrm{T}$ cell $\mathrm{ab}-$ sence on splenic FRCs. FRCs form specialized conduits in the spleen and $\mathrm{T}$ cells move along these conduits. These conduits guide the transfer of $\mathrm{T}$ cells from blood to the T-cell zone [13]. ER-TR7 plays a key role in the formation of conduits and in the spleen, it is only secreted by
FRCs [14]. We found that the expression of ER-TR7 was significantly downregulated in the spleens of nude mice (Figure 1A,B). We also analyzed the average values of fluorescence, the results show that ER-TR7 was significantly downregulated in the spleens of nude mice (Figure 1E); while in the spleen margins in BALB/c mice, the ER-TR7 formed a broad-banded structure which surrounded the $\mathrm{T}$ - and $\mathrm{B}$-cell zones and was not present in the nude mice (Figure 1C,D). These findings indicate that the in the absence of T cells FRCs will undergo structural abnormality.

\section{T cell absence affected secretion of FRC chemokine and homing of $\mathrm{T}$ cells}

To further clarify whether the dysfunction of FRCs occurs following the absence of $\mathrm{T}$ cells, we evaluated the expressions of CCL21 and CCL19, which in the spleen were expressed only in the T-cell zone. CCL21 and CCL19 were mainly secreted by FRCs and were the key chemokines that induced the initial homing of $\mathrm{T}$ cells to the spleen [15]. Their RNA and protein expression levels all were significantly downregulated (Figure 2B,C). Subsequently, protein localization analysis with fluorescence microscopy also
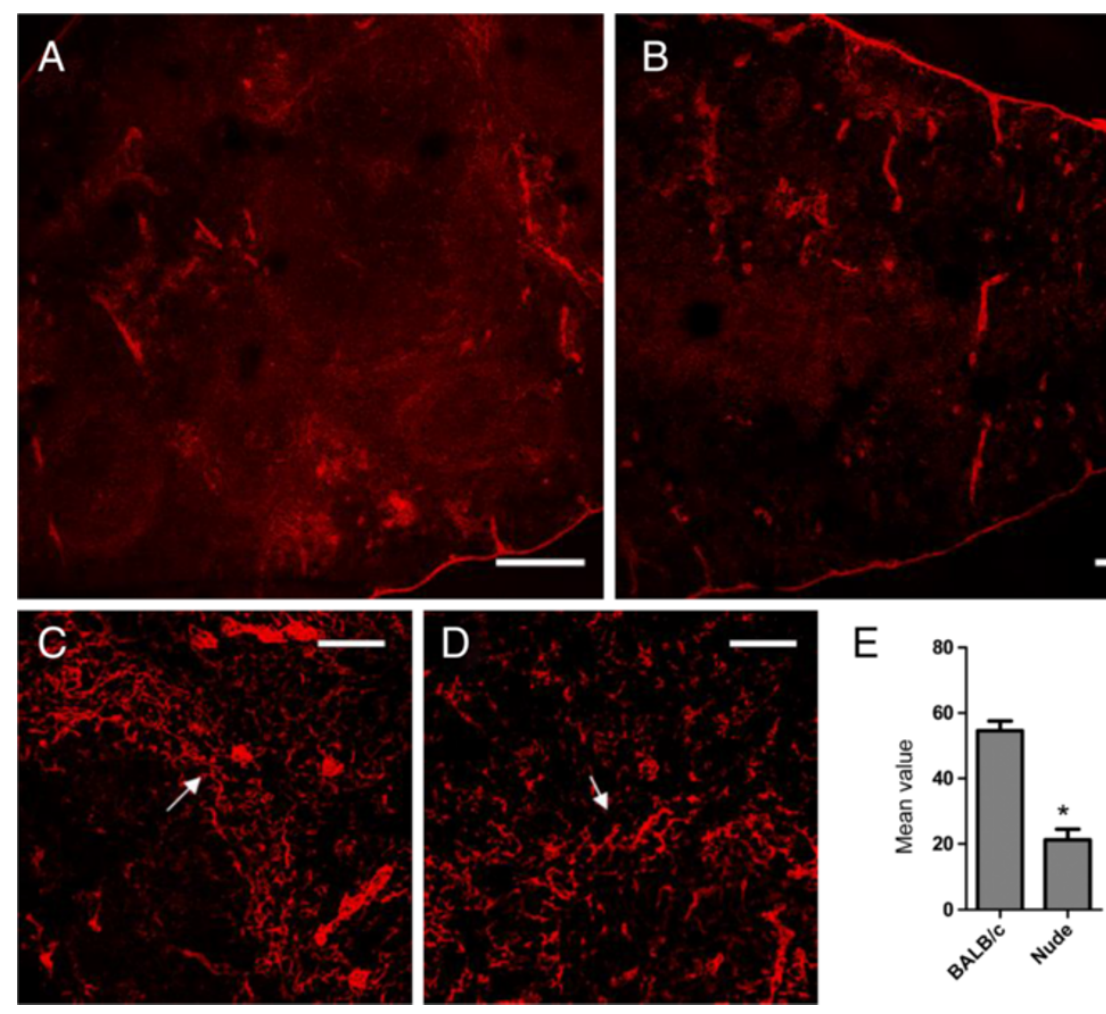

Figure 1 The conduits of FRCs were destroyed in the absence of T cells. Spleen cryostat sections from BALB/C mice (A) and nude mice (B) were stained for ER-TR7 (red =FRC-derived matrix protein), and imaged using confocal microscopy (Scale bars: 200um); Arrows show a higher magnification of the marginal zone of spleen from BALB/C mice (C) and nude mice (D) (Scale bars: 50um); We further analyzed the average fluorescence values of ER-TR7 (E). Data are representative of 5 mice per group. 


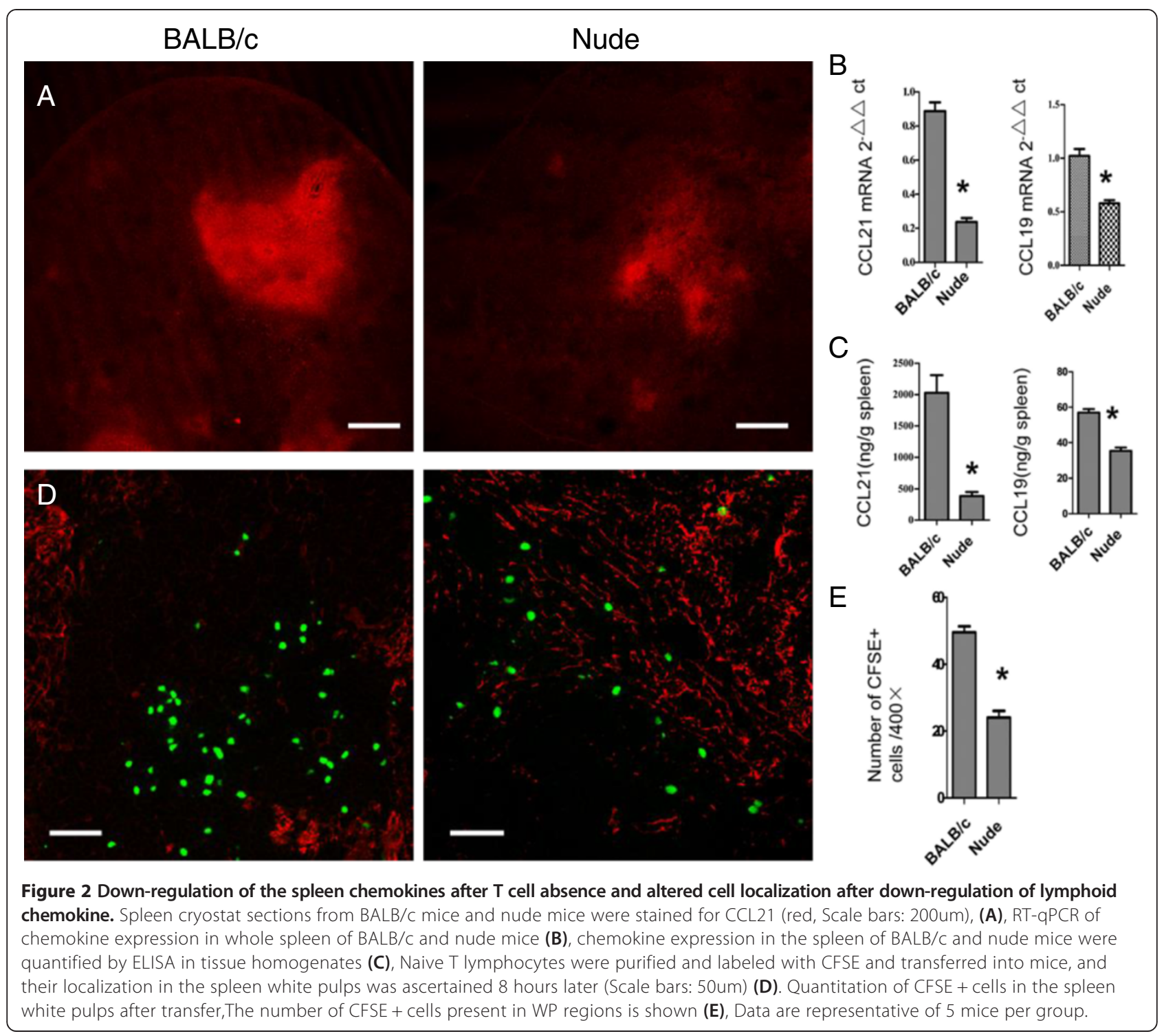

showed that the expressions of CCL21 and CCL19 were significantly downregulated (Figure 2A). We also examined the homing ability of T cells to the spleen; and, after ascertaining its specific localization to the white pulps, found that the count of CFSE-positive T cells in the splenic white pulps of nude mice was significantly reduced (Figure 2D,E).

\section{Transfusion of T cells recovered the splenic structure in nude mice}

We further examined whether transfusion of T cells would recover the splenic structure in nude mice. Following the transfusion of about 2-3 $\times 10^{7} \mathrm{~T}$ cells per week for 4 weeks, the proportions of $\mathrm{CD}^{+}$and $\mathrm{CD}^{+}$T-cells were greatly increased (Figure 3). Moreover, the expression of splenic ER-TR7 in nude mice was significantly improved and the structure was basically normal (Figure 4A,B). We additionally evaluated the expression of GP38, another marker of
FRCs, and it also was mostly recovered (Figure 4E). The mRNA and protein expressions of CCL21 and CCL19 were also largely increased after transfusion (Figure 4A,C,D). In addition, the homing ability of $\mathrm{T}$ cells to the spleen white pulps was prominently enhanced (Figure 5A, B). We also assessed the proportion of CFSE-positive cells homing to the whole spleen using flow cytometry (Figure 5C,D). The results show that the transfusion of $\mathrm{T}$ cells improved the homing ability of T cells to the spleen.

\section{Participation of LT-B in structural reconstruction of FRCs}

Previous research shows that loss of LT-B led to reduced secretion of IL-7 from FRCs. Since LT-B is mainly secreted by $\mathrm{T}$ cells, we further investigated the mechanism through which lymphocytes could contribute to reconstruct FRCs. We first analyzed the changes of LT-B mRNA and protein expressions and found that the expression levels in 


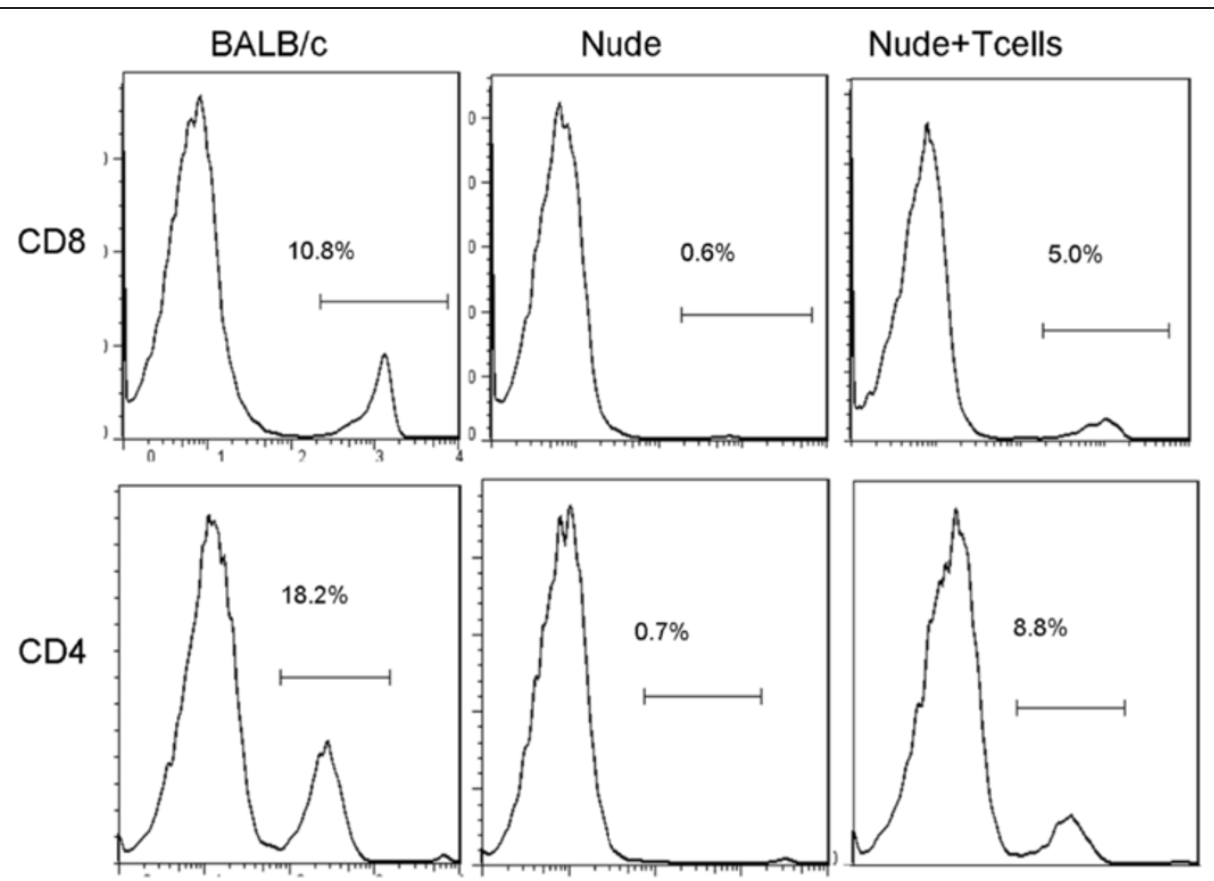

Figure 3 After transfusion of T cells, the proportion of T cells in the nude mice's spleens greatly increased. Naive T cells were purified and transferred into nude mice every week. After four weeks, percentages of CD8 ${ }^{+}$and $C D 4^{+} T$ cells in spleen were determined by FACS.

nude mice were significantly lower than in BALB/c mice (Figure 6A,B). The transfusion of $\mathrm{T}$ cells could upregulate the expression levels of LT-B mRNA and protein. During the transfusion, we blocked the LT-B receptor; however, the transfusion could not reconstruct the FRCs in nude mice (Figure 4A,B,E), or change the expressions of CCL21, and CCL19 (Figure 4C,D), or restore the homing ability of $\mathrm{T}$ cells (Figure 5).

\section{Discussion}

In the absence of T cells splenic FRCs undergo structural and functional abnormality, and the homing ability of $\mathrm{T}$ cells to the spleen weakens. Transfusion of $\mathrm{T}$ cells can remodel the structure and functions of FRCs and promote their recovery. These changes could be attributed to the T-cell-derived LT-B. Past research shows that T cells are critical during the adaptive immune response, even though the $\mathrm{T}$ cells capable of identifying specific antigens are produced in the SLOs [15-17]. The stromal cells (especially FRCs) in the SLOs are critical for maintaining the structural functions of lymphoid organs and in the production of specific $\mathrm{T}$ cells.

Earlier research about FRCs focuses on their effects on $\mathrm{T}$ cells, as FRCs maintain the homeostasis of $\mathrm{T}$ cells via the secretion of IL-7 $[8,15]$. Through their secretion of CCL19 and CCL21, FRCs also chemoattract T cells to the T-cell zone in the SLOs, and thus promote the encounter between T cells and antigen presenting cells. Other studies suggest that B cells can regulate the secretion of CCL21 by FRCs, and this occurs when mice are born [18]. Research about the effects of T cells on FRCs is limited, and mainly concerns HIV infection, but it is known that in the absence of lymphocyte secretion of IL-7 by FRCs is reduced and the homeostasis of T cells weakens [add reference]. The present study showed that in the absence of lymphocyte, not only IL-7, but also the structural functions of FRCs is significantly affected.

Firstly, we found that the T cell absence led to significantly lower expression and abnormal distribution of ER-TR7. Noteworthy, FRCs in the SLOs will form conduits that are critical for regulation of T-cell-specific immune response $[16,17]$. These conduits are formed jointly by FRCs and the FRC-secreted ECM; especially, ER-TR7 is a key ECM and in SLOs [14], ER-TR7 is only secreted by FRCs. Such conduits rapidly transport small molecules to the T-cell zone and also guide and support the migration of initial $\mathrm{T}$ cells to the T-cell zone $[19,20]$. As the codistribution of ER-TR7 and FRCs is highly consistent, ER-TR7 is commonly used as a marker of FRCs. The expression of ER-TR7 is downregulated with the absence of $\mathrm{T}$ cells, especially in the marginal zone, indicating that the FRC-formed conduits dissapeared in the absence of the $\mathrm{T}$ cell, probably further weakening the migration and survival of $T$ cells in the spleen.

Secondly, we found that in the absence of $\mathrm{T}$ cells the expressions of CCL19 and CCL21were downregulated. Interestingly, previous reports show that when lacking expression of CCL19 and CCL21 (ELC/SLC), naive T cells 


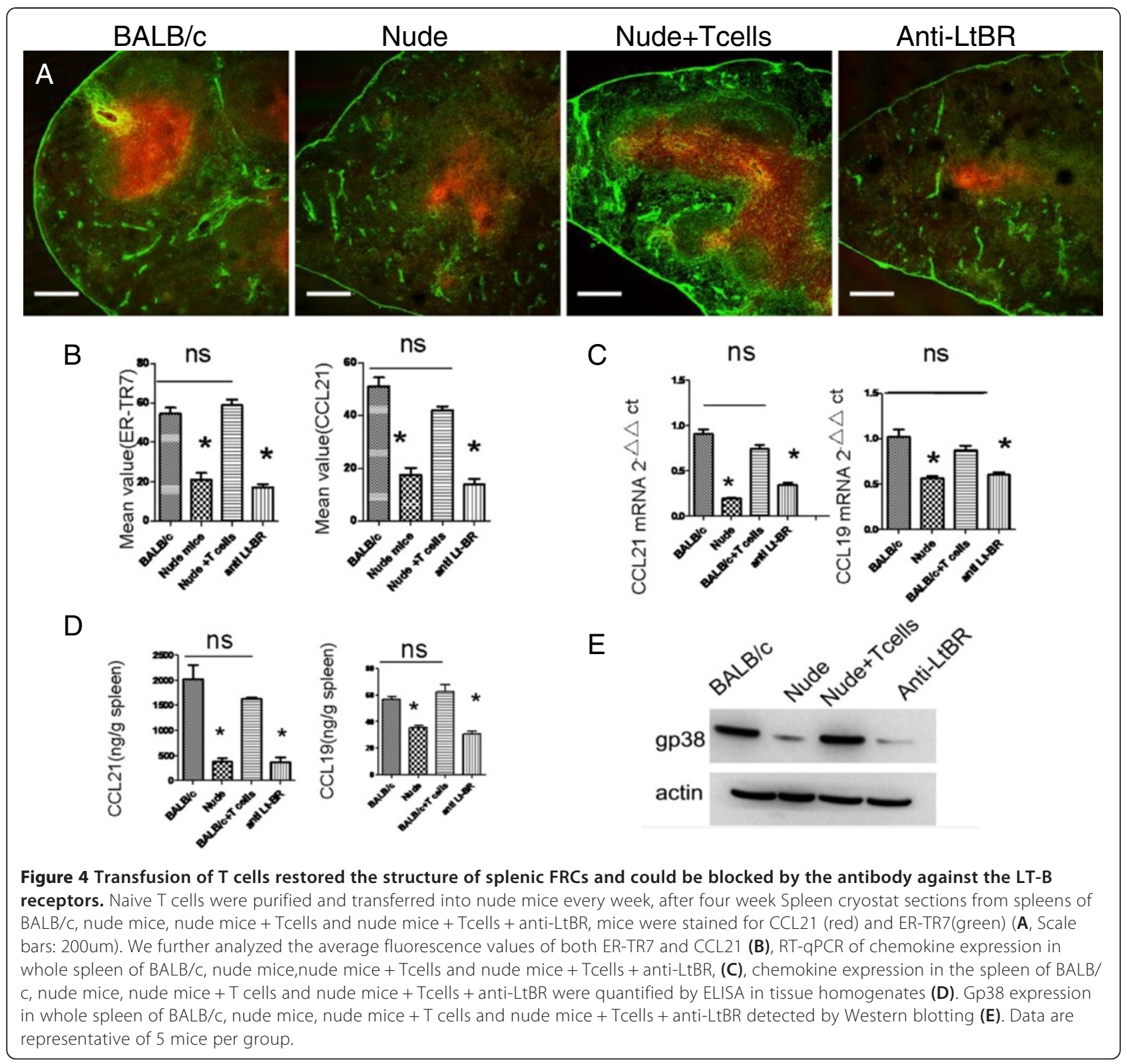

do not enter the T-cell zone efficiently [21,22]. Similarly, in CCR7-deficient mice, the cognate receptor for these chemokines, naive $\mathrm{T}$ cells cannot enter the T-cell zone, indicating the crucial role of this molecular interaction in regulating the access of naive $\mathrm{T}$ cell to this region. In the absence of $\mathrm{T}$ cell, the changes of FRC-secreted factors further weakened the homing ability of $\mathrm{T}$ cells. To validate this notion, we conducted the homing experiments, which yielded results that supported the above notion, as cells further damaged the homing ability of $\mathrm{T}$ cells and thereby weakened the immune response ability.

Finally, we found that the $\mathrm{T}$ cell absence significantly downregulated the LT-B level in SLOs, indicating that the reduced expressions of CCL21 and CCL19 due to T cell absence probably were induced by the absence of LT-B. These results are consistent with previous findings showing that the expression of IL-7 was significantly downregulated in the SLOs whose LT-B was knocked out and that LT-B was mainly secreted by T cells [23-25]. We also blocked the LT-B receptor and found that the transfusion of $\mathrm{T}$ cells did not restore the structure and functions of the spleen. This result indicated that the absence of T-cell-derived LT-B was mainly responsible for the structural and functional abnormality observed in FRCs after the $\mathrm{T}$ cell absence.

\section{Conclusions}

In the absence of $\mathrm{T}$ cell structural and functional $\mathrm{ab}-$ normalities appear in splenic FRCs of SLOs. The 

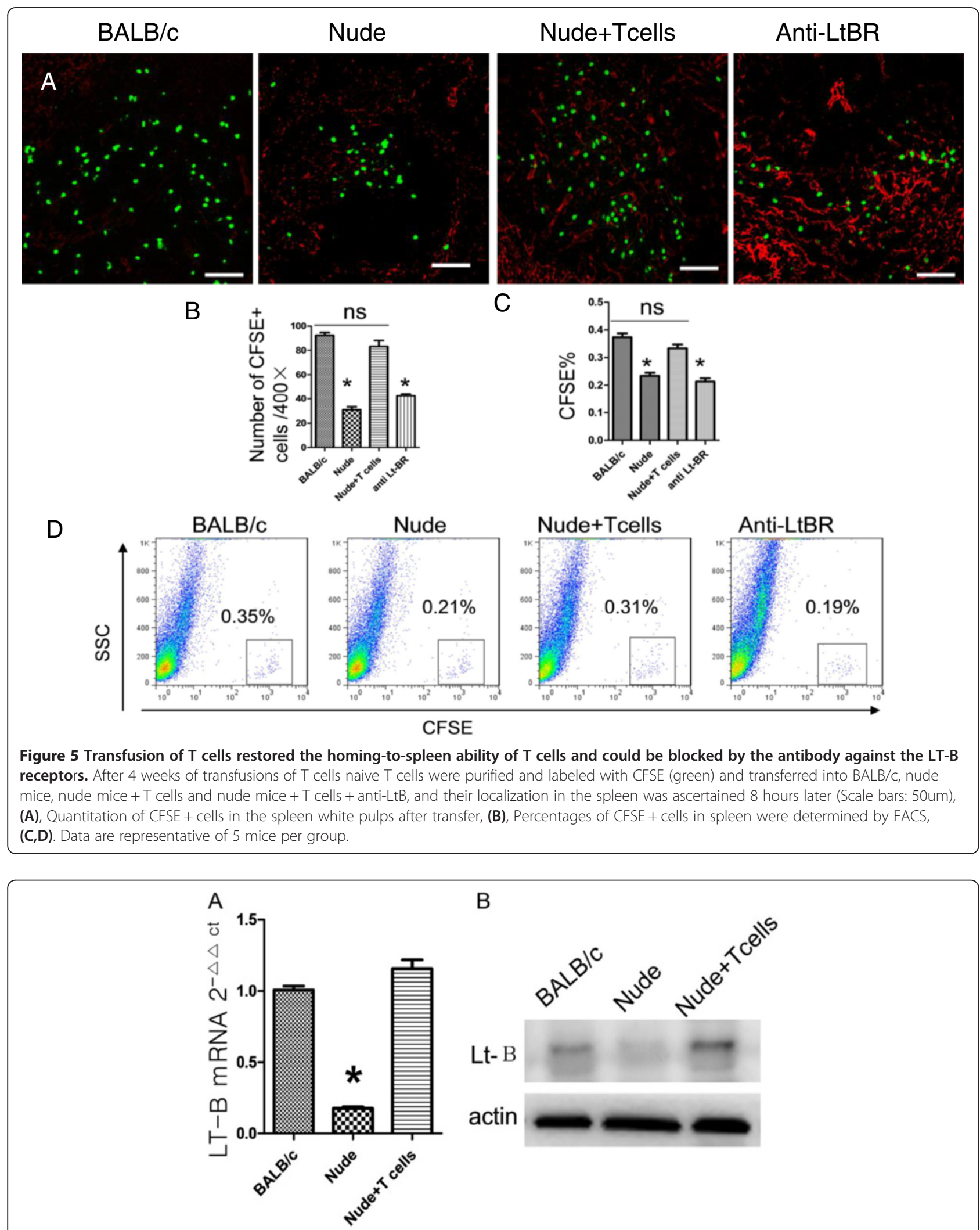

Figure 6 The T cell absence induced the downregulated expression of LT-B. Chemokine expression in whole spleen detected by RT-qPCR (A) and by Western blotting (B), and percentages of $C D 8^{+}$and $C D 4^{+} T$ cells determined by FACS (C) in BALB/C, nude mice and nude mice + T cells. 
transfusion of $\mathrm{T}$ cells restored the structure and functions, mainly because of the T cell-derived LT-B.

\section{Methods \\ Mice}

Six-week-old female BALB/c and nude mice were purchased from the Center of Experimental Animals of Third Military Medical University (TMMU, Chongqing, China). For in vivo antibody treatment, $200 \mu \mathrm{g}$ of mLT $\beta R-F c$ (Biogen Idec Inc., Cambridge, MA, USA) was injected at $10 \mathrm{~d}$ after $\mathrm{T}$ cell transfer, followed by $100 \mu$ g i.p. every $2 \mathrm{~d}$ [26]. The mice were maintained according to the TMMU Guidelines for Animal Experiments (SPF). All animal experimental protocols used in this study were in accordance with institutional Guidelines for Animal Experiments. The protocols used in the animal studies were approved by Institutional Ethics Committee of the Third Military Medical University.

\section{Adoptive transfers and cell migration in vivo}

For in vivo cell adoptive transfer, naive splenocytes were purified using anti-CD3 magnetic beads according to the manufacturer's instructions, and 2-3 $\times 10^{7}$ T cells were transferred into the mice every week. For in vivo cell migration, naive splenocytes were purified as above. Purified lymphocytes were labeled with $4 \mathrm{M}$ carboxy fluorescein succinimidyl ester (CFSE; Molecular Probes, Eugene, OR, USA) and $5 \times 10^{6}$ cells were transferred into each mouse [27]. After 8 hours, the mice were sacrificed and the spleens were removed for microscopic analysis. The number of CFSE + cells present in white pulp (WP) regions was assessed.

\section{Immunofluorescence microscopy}

Spleens were removed from mice and frozen in OCT (TissueTek, Elkhart, IN, USA). The cryostat sections $(10 \mu \mathrm{m})$ were fixed in ice-cold acetone for $10 \mathrm{~min}$ and then stained with the following antibodies: anti-mouse ER-TR7 (Santa Cruz Biotechnology Inc., CA, USA), and anti-mouse CCL21 (R\&D Systems, Minneapolis, MN, USA) [7]. The primary antibodies were detected by fluorescein isothiocyanate (FITC)-conjugated anti-rat (1:100, Beyotime Institute of Biotechnology, Beijing, China) or Cy3-conjugated anti-goat IgG (1:200, Beyotime). Average values of fluorescence were analyzed using LAS AF Lite.

\section{Enzyme-linked immunosorbent assay (ELISA)}

Tissues were harvested from mice and placed in phosphate buffer solution (PBS) supplemented with $1 \%$ bovine serum albumin and $1 \mathrm{mM}$ pheylmethylsulfonyl fluoride (PMSF, Sigma, St Louis, MO, USA). Subsequently, tissues were homogenized. CCL21 and CCL19 were detected using a DuoSet ELISA development kit (R\&DSystems) as per the manufacturer's instructions [7].

\section{Western blotting}

Tissues were harvested from mice and placed in RIPA buffer (Beyotime) with $1 \mathrm{mM}$ PMSF (Beyotime); and then homogenized. The lysates were normalized to equal amounts of protein, and the proteins were separated by $15 \%$ gradient sodium dodecyl sulfate-polyacrylamide gel electrophoresis (SDS-PAGE), transferred to polyvinylidene fluoride (PVDF) and probed with Lt-B (Santa Cruz) or gp38 (R\&D Systems). Detection was conducted by incubation with species-specific horseradish peroxidase (HRP)-conjugated secondary antibodies. Immunoreactive bands were visualized by enhanced chemiluminescence (Millipore, Billerica, MA, USA).

\section{Real-time quantitative reverse transcription polymerase chain reaction ( $R T-q P C R$ )}

PCR primer pairs, including their specific target gene, orientation (F: forward, $\mathrm{R}$ : reverse), and sequence were as follows: CCL21 (F ccctggacccaaggcagt, $R$ ggcttagagtgcttccggg), CCL19 (F ctgcctcagattatctgccat, $\mathrm{R}$ tcattagcacccccagagt), actin (F cctgaggctctttccagcc $\mathrm{R}$ agaggtctttacggatgtcaacgt) [7]. Whole spleens were placed in Trizol (Invitrogen, San Diego, CA, USA) and total RNA was extracted according to the manufacturer's instructions. Real-time RT-qPCR was performed for total chemokine mRNA using SYBR Green (Takara Bio Inc., Japan) and detected using a BioRad RT-qPCR analyzer. Conditions were as follows: $95^{\circ} \mathrm{C}$ for 30 s, then 40 cycles of $95^{\circ} \mathrm{C}$ for $5 \mathrm{~s}, 59^{\circ} \mathrm{C}$ for $34 \mathrm{~s}$, then $95^{\circ} \mathrm{C}$ for $15 \mathrm{~s}, 60^{\circ} \mathrm{C}$ for $60 \mathrm{~s}$, and $95^{\circ} \mathrm{C}$ for $15 \mathrm{~s}$. Expression was quantified with actin as a reference as $-\Delta \Delta \mathrm{CT}$, as per manufacturer's instructions (Applied Biosystems).

\section{Statistical analysis}

Statistical analysis was performed with two-tailed unpaired t-test using Prism (Graphpad Software Inc., San Diego, CA, USA). Each group contained $\mathrm{N}=5$ mice. Nude mice were randomly allocated to each group.

\section{Competing interests}

The authors declare that they have no competing interests.

\section{Authors' contributions}

$B G$ and $B Z$ designed the study. $L Z$ and $L L$ performed experiments and prepared the manuscript. JG and $Y Y$ processed the data. $\mathrm{CH}$ was involved in the preparation and revision of this manuscript. All authors approve the final version of this manuscript.

\footnotetext{
Acknowledgements

This work was supported by National Nature Science Foundation of China (grant nos.81070018, 81472648 and 81222031), by National Science Foundation of China (NSFC No. 81072421), by Natural Science Foundation Project of CQ (CSTC No. 2011BB5040), by the outstanding Youth Scientist Foundation of Chongqing (no. CSTC, 2008BA5035) and by National Key Basic Research Program of China (973 program, grant nos. 010 CB529404 and 2012(B526603).
}

Received: 29 April 2014 Accepted: 13 August 2014

Published online: 30 September 2014 


\section{References}

1. Mueller SN, Germain RN: Stromal cell contributions to the homeostasis and functionality of the immune system. Nat Rev Immunol 2009, 9:618-629.

2. Turley SJ, Fletcher AL, Elpek KG: The stromal and haematopoietic antigen-presenting cells that reside in secondary lymphoid organs. Nat Rev Immunol 2010, 10:813-825.

3. Klaus GG, Humphrey JH, Kunkl A, Dongworth DW: The follicular dendritic cell: its role in antigen presentation in the generation of immunological memory. Immunol Rev 1980, 53:3-28.

4. Link A, Vogt TK, Favre S, Britschgi MR, Acha-Orbea H, Hinz B, Cyster JG, Luther SA: Fibroblastic reticular cells in lymph nodes regulate the homeostasis of naive T cells. Nat Immunol 2007, 8:1255-1265.

5. Sixt M, Kanazawa N, Seig M, Samson T, Roos G, Reinhardt DP, Pabst R, Lutz $M B$, Sorokin L: The conduit system transports soluble antigens from the afferent lymph to resident dendritic cells in the T cell area of the lymph node. Immunity 2005, 22:19-29.

6. Bajenoff M, Egen JG, Koo LY, Laugier JP, Brau F, Glaichenhaus N, Germain $\mathrm{RN}$ : Stromal cell networks regulate lymphocyte entry, migration, and territoriality in lymph nodes. Immunity 2006, 25:989-1001.

7. Mueller SN, Hosiawa-Meagher KA, Konieczny BT, Sullivan BM, Bachmann MF, Locksley RM, Ahmed R, Matloubian M: Regulation of homeostatic chemokine expression and cell trafficking during immune responses. Science 2007 317:670-674

8. Onder L, Narang P, Scandella E, Chai Q, lolyeva M, Hoorweg K, Halin C Richie E, Kaye P, Westermann J: IL-7-producing stromal cells are critical for lymph node remodeling. Blood 2012, 120:4675-4683.

9. Fry TJ, Mackall CL: The many faces of IL-7: from lymphopoiesis to peripheral T cell maintenance. J Immunol 2005, 174:6571-6576.

10. Junt T, Tumanov AV, Harris N, Heikenwalder M, Zeller N, Kuprash DV, Aguzzi A, Ludewig B, Nedospasov SA, Zinkernagel RM: Expression of lymphotoxin beta governs immunity at two distinct levels. Eur J Immunol 2006, 36:2061-2075.

11. Tumanov AV, Kuprash DV, Nedospasov SA: The role of lymphotoxin in development and maintenance of secondary lymphoid tissues. Cytokine Growth Factor Rev 2003, 14:275-288.

12. Zeng M, Paiardini M, Engram JC, Beilman GJ, Chipman JG, Schacker TW, Silvestri G, Haase AT: Critical role of CD4 T cells in maintaining lymphoid tissue structure for immune cell homeostasis and reconstitution. Blood 2012, 120:1856-1867.

13. Bajenoff M, Glaichenhaus N, Germain RN: Fibroblastic reticular cells guide T lymphocyte entry into and migration within the splenic T cell zone. J Immunol 2008, 181:3947-3954.

14. Katakai T, Hara T, Sugai M, Gonda H, Shimuzu A: Lymph node fibroblastic reticular cells construct the stromal reticulum via contact with lymphocytes. J Exp Med 2004, 200:783-795.

15. Malhotra D, Fletcher AL, Astarita J, Lukacs-Kornek V, Tayalia P, Gonzalez SF, Elpek KG, Chang SK, Knoblich K, Hemler ME: Transcriptional profiling of stroma from inflamed and resting lymph nodes defines immunological hallmarks. Nat Immunol 2012, 13:499-U107.

16. Levy Y, Lacabaratz C, Weiss L, Viard JP, Goujard C, Lelievre JD, Rouzioux C, Avettand-Fenoel V: Enhanced T cell recovery in HIV-adults through IL-7 treatment. J Clin Investig 2009, 119:997-1007.

17. den Haan JM, Mebius RE, Kraal G. Stromal cells of the mouse spleen. Front Immunol 2012, 3:201-201.

18. Ngo VN, Cornall RJ, Cyster JG: Splenic T zone development is B cell dependent. J Exp Med 2001, 194(11):1649-1660.

19. Malhotra D, Fletcher AL, Turley SJ: Stromal and hematopoietic cells in secondary lymphoid organs: partners in immunity. Immunol Rev 2013, 251:160-176.

20. Siegert S, Luther SA: Positive and negative regulation of $\mathrm{T}$ cell responses by fibroblastic reticular cells within paracortical regions of lymph nodes. Front Immunol 2012, 3:285-285.

21. Gretz JE, Kaldjian EP, Anderson AO, Shaw S: Sophisticated strategies for information encounter in the lymph node: the reticular network as a conduit of soluble information and a highway for cell traffic. J Immunol 1996, 157:495-499.

22. Luther SA, Bidgol A, Hargreaves DC, Schmidt A, Xu Y, Paniyadi J, Matloubian M, Cyster JG: Differing activities of homeostatic chemokines CCL19, CCL21, and CXCL12 in lymphocyte and dendritic cell recruitment and lymphoid neogenesis. J Immunol 2002, 169:424-433.
23. Koni PA, Sacca R, Lawton P, Browning JL, Ruddle NH, Flavell RA: Distinct roles in lymphoid organogenesis for lymphotoxins alpha and beta revealed in lymphotoxin beta-deficient mice. Immunity 1997, 6:491-500.

24. Korner $H_{1}$ Cook M, Riminton DS, Lemckert FA, Hoek RM, Ledermann B, Kontgen F, Fazekas de St Groth B, Sedgwick JD: Distinct roles for lymphotoxin-alpha and tumor necrosis factor in organogenesis and spatial organization of lymphoid tissue. Eur J Immunol 1997, 27:2600-2609.

25. Zeng M, Smith AJ, Wietgrefe SW, Southern PJ, Schacker TW, Reilly CS, Estes JD, Burton GF, Silvestri G, Lifson JD: Cumulative mechanisms of lymphoid tissue fibrosis and T cell depletion in HIV-1 and SIV infections. J Clin Investig 2011, 121:998-1008.

26. Yang C-Y, Vogt TK, Favre S, Scarpellino L, Huang H-Y, Tacchini-Cottier F, Luther SA: Trapping of naive lymphocytes triggers rapid growth and remodeling of the fibroblast network in reactive murine lymph nodes. Proc Natl Acad Sci U S A 2014, 111:E109-E118.

27. Soudja SM, Henri S, Mello M, Chasson L, Mas A, Wehbe M, Auphan-Anezin $\mathrm{N}$, Leserman L, Van den Eynde B, Schmitt-Verhulst A-M: Disrupted lymph node and splenic stroma in mice with induced inflammatory melanomas is associated with impaired recruitment of T and dendritic cells. Plos One 2011,6

\section{doi:10.1186/s12865-014-0033-4}

Cite this article as: Zhao et al.: T lymphocytes maintain structure and function of fibroblastic reticular cells via lymphotoxin (LT)-B. BMC Immunology 2014 15:33.

\section{Submit your next manuscript to BioMed Central and take full advantage of:}

- Convenient online submission

- Thorough peer review

- No space constraints or color figure charges

- Immediate publication on acceptance

- Inclusion in PubMed, CAS, Scopus and Google Scholar

- Research which is freely available for redistribution 